\title{
O XIRÊ DA LEITURA: MULHERES NEGRAS GRAFANDO MEMÓRIAS EM LETRAS DE POESIA - COMO UM ESPAÇO DE FALA, ESCUTA E CURA
}

FERREIRA, Luzia Gomes ${ }^{1}$

CASTRO, Julie ${ }^{2}$

RESUMO: Compreendendo a importância do tripé basilar da Universidade Pública Brasileira que é Ensino, Pesquisa e Extensão, neste artigo vamos falar do Projeto de Extensão Xirê da Leitura: Mulheres Negras Grafando memórias em Letras de Poesia ${ }^{3}$, criado no âmbito do curso de Museologia da Universidade Federal do Pará (UFPA) em 2019 e desenvolvido em parceria com a Livraria Ifá - Casa do Saber, com o objetivo de criar um espaço de memória com leituras e debates das obras de poetas negras brasileiras e estrangeiras, numa perspectiva de possibilitar a descolonização do olhar, do ler e do escutar. É possível constatar que no contexto brasileiro a poesia, enquanto expressão artística ainda possui uma ínfima representação de poetas negras nos espaços oficializados de produção, distribuição e fruição da escrita literária. Raro, também, é compreender a poesia produzida por mulheres negras como um patrimônio do nosso tempo, assim como é incomum termos instituições museológicas dedicadas às memórias de poetas negras no Brasil. Acreditamos na importância de tecermos uma rede artística de poetas negras abertas ao diálogo e com o nosso protagonismo negro, uma vez que devido ao sexismo e ao racismo estrutural da sociedade brasileira, nós, mulheres negras ainda não estamos representadas e apresentadas dignamente na maioria dos espaços oficiais de enunciação das memórias na capital paraense e nem nos seletos setores da produção literária.

PALAVRAS-CHAVE: Memórias, Museologia, Poetas Negras, Poesia, Xirê.

\section{THE READING XIRÊ: BLACK WOMEN WRITING MEMORIES IN POETRY LYRICS - AS A SPACE FOR SPEECH, LISTENING AND HEALING}

\footnotetext{
${ }^{1}$ Poeta e Docente do Curso de Museologia da Faculdade de Artes Visuais (FAV) do Instituto de Ciências da Arte (ICA) da UFPA. E-mail: lu.ayeomi@gmail.com

${ }^{2}$ Graduanda em Museologia (FAV/ICA/UFPA. E-mail: castrojulie18@gmail.com

${ }^{3}$ Este projeto foi contemplado no Edital PIBEX/2019 da PROEX/UFPA.
}

Jangada | nr. 15, jan/jun, 2020 | ISSN 2317-4722 
ABSTRACT: Understanding the importance of the basic tripod of the Brazilian Public University, which is Teaching, Research and Extension, in this article we will talk about the Xirê Reading Extension Project: Black Women Graffiti memories in Poetry, created in the course of the Museum of the Federal University of Para (UFPA) in 2019 and developed in partnership with book store Ifá - House of knowledge, in order to create a memory space with readings and debates of the works of Brazilian and foreign black poets, with a view to enabling the decolonization of the look, make read and make listen. It can be seen that no Brazilian context is poetry, while artistic expression still has a maximum representation of black poets in the official spaces of production, distribution and enjoyment of literary writing. Rare, too, understands the poetry exhibited by black women as a heritage of our time, as well as the following terms and conditions museum institutions dedicated to the memories of black poets in Brazil. We believe in the importance of weaving an artistic network of black poets open to dialogue and with our black protagonism, since due to the sexism and structural racism of Brazilian society, we, black women are not yet represented and worthily in most of the official spaces. enunciation of memories in the capital of Para and not in the sectors of literary production.

KEYWORDS: Memoirs, Museology, Black poets, Poetry, Xirê.

\section{AS PALAVRAS EM MOVIMENTO NO XIRÊ}

Xirê é um ritual do Candomblé no qual se faz uma roda e as iniciadas e os iniciados dançam em círculo ao som dos atabaques e agogô para louvar as Divindades do Panteão Afro-Brasileiro. Ao mesmo tempo, esse ritual é um convite para que as Entidades desçam à terra a partir dos corpos das suas filhas e dos seus filhos, para celebrar em festa a Yabá ${ }^{4}$ ou o Aboró ${ }^{5}$ que está sendo homenageada/o no dia. Partindo do princípio da roda, na qual todas e todos podem se olhar horizontalmente, em que a dança e a música é um fator de integração, harmonização e comunicação entre as pessoas e os Orixás, mas também de reavivamento das memórias negroafricanas ancestrais, o Projeto de Extensão Xirê da Leitura: Mulheres Negras Grafando Memórias em Letras de Poesia adota a roda de leitura oral como canto, dança, socialização e reverência à poesia das mulheres negras, como mensageiras das Yabás que se fazem presente em todas nós que trazemos no corpo as marcas da negritude.

\footnotetext{
${ }^{4}$ Orixás femininos.

${ }^{5}$ Orixás masculinos. 
O Xirê foi criado em 2019 no âmbito do curso de Bacharelado em Museologia (FAV/ICA/UFPA), com Portaria No 041/2019 e coordenado pela Professora Doutora Luzia Gomes Ferreira e a Museóloga Mestra Josiane Martins, tendo como bolsista extensionista a discente/pesquisadora Julie Castro. Em 2020 a coordenação fica a cargo da referida professora e da historiadora e poeta Roberta Tavares. Este projeto surge pela lacuna existente na Museologia em estabelecer diálogos com as escritas literárias produzidas por mulheres negras. As teorias e práticas museológicas, na maior parte do tempo, ainda olham para a literatura a partir da musealização das casas de escritores/escritoras, geralmente brancos/brancas. Nós percebemos que a partir da prosa e da poesia podemos ir além da salvaguarda de objetos, mas também refletirmos acerca de outras narrativas das memórias, dos patrimônios, do colonialismo, do sexismo, do racismo, das efemeridades do tempo, da poética da vida, entre tantas outras questões que a arte literária nos leva a pensar. Muitas vezes, a busca incessante por teorias descolonizantes que nos auxiliem na construção do nosso pensamento museológico, fez-nos recorrer aos textos literários, o que possibilitou um alargarmento das nossas percepções e reflexões acadêmicas. Por isso, em nosso Projeto de Extensão, lemos poesia para entender o mundo!

De acordo com a escritora e doutora Conceição Evaristo: "No corpus da escrita de mulheres negras está a criação imagética da auto-representação de um corpo que não é apenas descrito, mas, antes de tudo, vivido. Um corpo vivido em sua própria escrita, uma escrita vivida por um corpo que se inscreve/escreve em sua escrevivência.” (EVARISTO, 2019). O pensamento de Evaristo revela os princípios da escrita para a maioria das mulheres negras que trilham os caminhos da literatura. Contudo, numa sociedade como a brasileira, estruturada sobre pilares racistas e sexistas, as escrevivências das mulheres negras, na maioria das vezes ficaram invisibilizadas e silenciadas nos espaços hegemônicos literários, acadêmicos e museológicos. No contexto brasileiro é inconcebível anular os efeitos nefastos do racismo e do sexismo no âmbito das artes, que dita o que é arte, o que devemos ler como uma obra de arte literária e acima de tudo, coloniza o nosso olhar a ponto de elegermos intencionalmente os corpos brancos como produtores de arte. A poeta e professora doutora Lívia Natália ao discorrer sobre racismo afirma o seguinte:

O racismo nesse país, que se diz uma democracia racial, é estruturante de todas as relações. Quando eu entro numa sala, não entra apenas uma mulher, entra uma mulher negra e as pessoas me leem com a máquina do racismo montada, 
mesmo que essa pessoa não seja racista. Espera-se um determinado comportamento, uma determinada fala de uma determinada mulher negra. Não é raro uma pessoa se surpreender quando eu não sou a garçonete, quando eu não sou a vendedora, quando eu não sou a empregada doméstica. Quando eu abro a porta do meu apartamento para alguém fazer algum serviço, há um espanto pelo fato de ser eu a dona do apartamento e não a empregada. (...) Então, o racismo está presente do momento que eu abro os olhos ao momento que eu os fecho. E se eu durmo ele está nos sonhos, nos pesadelos. Não posso dizer de maneira nenhuma que o racismo não interfere diretamente naquilo que eu escrevo. (NATÁLIA, 2017, p. 282).

As reflexões da poeta e professora Lívia Natália nos fazem perceber que o racismo é uma das vigas opressoras nas edificações das relações sociais no Brasil, que atravessa todos os andares do tecido cotidiano, sustentando as hierarquias raciais dentro dos sistemas coletivos, incluindo o sistema oficial da arte e do ensino. "O racismo segue em curso... roubando o sorriso... surrupiando a alegria... desencantando a beleza... enfeiando os dias... desmantelando os corpos... e(S)trangulando as cabeças... ofertando a morte!” (GOMES, 2019, sítio web). E como a artista e teórica Grada Kilomba nos alerta: "O racismo é uma realidade violenta." (KILOMBA,2019, p. 71). Estar em eventos literários ou acadêmicos e sempre poder contar quantas mulheres negras estão à mesa em posição de destaque, enquanto agentes reflexivas e não na subalternização de "objetos de estudo", é uma das materializações do racismo epistêmico que produz apagamentos e determina as brancas escolhas que fazemos nos espaços oficiais de produção dos conhecimentos científicos e artísticos.

A intelectual Carla Akotirene enfatiza que "[...] a diáspora negra deve buscar caminhos discursivos em atenção aos acordos estabelecidos com os antepassados. [...] a língua escravizada esteve amordaçada, politicamente, impedida de tocar seu idioma, beber da própria fonte epistêmica cruzada de mente-espírito." (AKOTIRENE, 2018, p. 16). Por isso, apontar os silenciamentos e apagamentos das mulheres negras na academia, no sistema da arte literária, nos espaços museais, não significa que as pessoas negras tenham o objetivo de deslegitimar e substituir autores/autoras brancos/brancas e artistas brancos/brancas por negros/as, pois não somos epistemicidas. Propomos que as universidades públicas, as feiras literárias e os museus, realmente em suas práticas e não apenas nas teorias em artigos científicos, operem no sentido mais amplo e profundo do respeito à diversidade. Há corpos não brancos, não heteronormativos 
e não europeus, produzindo conhecimentos acadêmicos e artísticos e esses saberes precisam ser reconhecidos pelas instituições de ensino e cultura de forma simétrica e com equidade. No entanto, sabemos que estamos travando disputas de narrativas e nem sempre esse diálogo será harmônico, até mesmo porque o racismo não harmoniza as relações sociais e raciais no Brasil, pois, como ressalta a escritora Ana Maria Gonçalves: “O que agora pode ser apenas rachadura há de se tornar ruptura, porque nada volta a se recompor do jeito que era antes. Aos que estão atentos e dispostos a fazer o movimento: o desconforto é bom. É o que nos faz avançar.” (GONÇALVES, 2017, [s/n]).

Compreendemos a necessidade de avançar no sentido de não fazer apenas a denúncia, mas também de apresentarmos propostas para a reversão desse quadro de silenciamentos, apagamentos e ausências, o que já vem sendo feito há anos pelos Movimentos Negros. Nesse sentido, o Xirê tem como pauta evidenciar as memórias das mulheres negras para além dos espaços expositivos dos museus, nos quais na maioria das vezes não somos apresentadas e muito menos representadas dignamente. $\mathrm{O}$ direito à memória, a partir da poesia de poetas negras, deve está na ordem do dia nos cursos de Museologia, se realmente acreditamos em memórias plurais e na descolonização das teorias e práticas museológicas dentro e fora dos espaços museais oficializados.

Para muitas mulheres negras, a escrita literária é uma forma de libertação no existir. No entanto, sabemos que as nossas palavras, na maioria das vezes não alcançam uma grande plateia, devido aos meios de produção e distribuição oficiais que na maior parte do tempo ainda privilegiam os escritores brancos e as escritoras brancas. Ultimamente com o advento de algumas escritoras negras no mercado editorial, há uma equivocada sensação de que temos uma "revolução literária enegrecida" dentro do sistema oficial da literatura: ledo engano! Durante o desenvolvimento do Xirê da Leitura: Mulheres Negras Grafando Memórias em Letras de Poesia, observamos que, no quesito poesia, a publicação de poetas negras ainda é ínfima. Se fizermos recortes regionais, por exemplo, aqui no norte, especificamente em Belém do Pará é praticamente inexistente. Evidentemente, que há outras formas de publicação, como fanzines e blogs, mas aqui estamos considerando um dos suportes mais clássicos da escrita: o livro impresso. Outra questão que veio à tona também foi a dificuldade de acessarmos trabalhos de poetas negras de outros países da América Latina, que não seja o Brasil, identificamos como essas traduções ocorrem lentamente. A circulação dessas escritas negras dos países latinoamericanos, que não falam português no cenário literário brasileiro, ainda é rara. 
Sabemos o quanto a escrita funciona como uma ferramenta política de poder, construtora de valores e imposição das estruturas de pensamentos no Ocidente, seja na academia ou na arte literária. Escrever para as mulheres negras é um processo transformador, porque as palavras materializadas no papel também são ações de existência e resistência no contexto diaspórico. O texto também é voz, é o nosso corpo negro em movimento e em algum momento seremos ouvidas, mesmo que não seja no instante em que desejamos e por quem queremos que nos escute respeitosamente. As palavras grafadas ou oralizadas são conservadas na reserva técnica mutável do tempo. Em diálogo com Glória Anzaldúa, pensamos na importância da escrita para as mulheres não brancas:

Por que sou levada a escrever? Porque a escrita me salva da complacência que me amedronta. Porque não tenho escolha. Porque devo manter vivo o espírito de minha revolta e a mim mesma também. Porque o mundo que crio na escrita compensa o que o mundo real não me dá. No escrever coloco ordem no mundo, coloco nele uma alça para poder segurá-lo. Escrevo porque a vida não aplaca meus apetites e minha fome. Escrevo para registrar o que os outros apagam quando falo, para reescrever as histórias mal escritas sobre mim, sobre você. Para me tornar mais íntima comigo mesma e consigo. Para me descobrir, preservar-me, construir-me, alcançar autonomia. Para desfazer os mitos de que sou uma profetisa louca ou uma pobre alma sofredora. Para me convencer de que tenho valor e que o que tenho para dizer não é um monte de merda. Para mostrar que eu posso e que eu escreverei, sem me importar com as advertências contrárias. Escreverei sobre o não dito, sem me importar com o suspiro de ultraje do censor e da audiência. Finalmente, escrevo porque tenho medo de escrever, mas tenho um medo maior de não escrever (ANZALDÚA, 2000, p. 232).

As escritas das mulheres negras apresentam-nos um lado muitas vezes esquecido das nossas memórias museológicas e patrimoniais selecionadas e oficializadas pelo Estado. Porém, com o diferencial de que somos nós falando por nós mesmas: “[...] para todas nós é necessário ensinar com a vida e com as palavras essas verdades que acreditamos e conhecemos mais além do entendimento. Porque só assim sobreviveremos, participando num processo de vida criativo, contínuo e em crescimento" (LORDE, 1977, [s/n]). Para além de escrever, também necessitamos de auscultação e representatividade! Quem está disposta/o a nos ouvir com 
respeito? Estamos ofertando escuta atenciosa e afetuosa aos corpos nãobrancos nos espaços hegemônicos de poder? Em pleno século XXI qual é a escrita literária realmente aceita? Quem tem direito a escrever, a falar e a ser escutada/o? Grada Kilomba, ressalta que:

Há muito tempo temos falado e produzido conhecimento independente, mas quando há assimetria de grupos nopoder, há também assimetria no acesso que os grupos têm a recursos necessários para implementar suas próprias vozes [...] Porque nos falta controle sobre tais estruturas, a articulação de nossas próprias perspectivas fora de nossos grupos torna-se extremamente difícil, se não irrealizável. Como resultado, o trabalho de escritoras/es e intelectuais negras/os permanece em geral, fora do corpo acadêmico e de suas agendas [...]. (KILOMBA, 2019, p. 52-53).

Pensar as escritas de mulheres negras seja na prosa ou na poesia como uma possibilidade concreta de pluralizar as narrativas sobre conhecimentos e memórias que muitas vezes não estão materializadas nos objetos musealizados, e nem nos bens móveis e imóveis tombados pelo Instituto do Patrimônio Histórico e Artístico Nacional (IPHAN), é compreender que as memórias individuais e coletivas também são construídas a partir das palavras e das imagens criadas pela prosa e poesia. Escrever é uma forma de estar no mundo, porque a palavra é existência e dilui fronteiras, criando pontes de ligação dos afetos em rede. Apesar das agruras, as mulheres negras bordaram palavras de beleza com letras delicadas de ternura. É preciso ler e escutar mulheres negras nas artes e nas ciências!

\section{A POESIA DE MULheres NEGRAS ECOANDO NO TEMPO DAS ÁGUAS DE CHUVAS E RIOS}

O Projeto de Extensão Xirê da Leitura: Mulheres Negras Grafando Memórias em Letras de Poesia se propõe a criar um espaço de memórias com leituras e debates das obras de poetas negras brasileiras e estrangeiras, compreendendo essa literatura como um patrimônio do nosso tempo, assim como um lugar de enunciação e de visibilização da poesia escrita por mulheres negras brasileiras e estrangeiras. Também procuramos ofertar às pessoas um pouco de reflexão com encanto nesse dia-a-dia meio sem jeito, meio bagunçado, em que é preciso que as palavras poéticas adentrem as frestas da cidade em tempos de tensões políticas e sociais. Trazer para o campo da Museologia reflexões e ações acerca da poesia produzida por mulheres negras é 
importante para pensarmos e propormos, em parceria com as/os discentes dentro e fora da sala de aula, processos de musealização descolonizantes e a (re)-criação de epistemologias antirracistas e antissexistas no campo museológico. Porque em pleno século XXI ainda vivemos uma necropolítica das memórias negras na sociedade brasileira. As escritas de mulheres negras são possibilidades concretas de contra narrativas imagéticas e históricas, humanizadoras das vidas negras. É a busca constante pelo direito de olhar, de escrever, de narrar e de se ver, traçando assim outras estéticas no tempo, protagonizadoras das nossas subjetividades.

No Xirê da Leitura: Mulheres Negras Grafando Memórias em Letras de Poesia fazemos encontros mensais, geralmente numa sexta-feira, na Livraria Ifá, no bairro do Marco, na cidade de Belém do Pará e realizamos o Xirê Literário, no qual duas convidadas (mulheres negras) declamam poemas de poetas negras. Os livros das autoras são selecionados com antecedência e repassados para as declamadoras. Após escutarmos os poemas das escritoras indicadas para a noite, abrimos a roda para dialogarmos sobre os poemas, os livros, as autoras e a vida. A cada sessão realizada, percebemos a importância da poesia na vida das pessoas, especialmente para as nossas, enquanto mulheres negras. Como nos disse Audre Lorde: "Para mulheres, então, poesia não é um luxo. Ela é uma necessidade vital de nossa existência. Ela forma a qualidade da luz dentro da qual predizemos nossas esperanças e sonhos em direção à sobrevivência e mudança [...]” (LORDE, 1977, [s/n]). No desenvolvimento desse trabalho é prazeroso percebermos mulheres negras e não negras, mas também homens que estão na plateia entrelaçando suas vidas com as palavras poéticas que ouviram.

Em 2019, lemos as seguintes poetas, livros e fanzines:

\begin{tabular}{|l|l|}
\hline \multicolumn{1}{|c|}{ Poetas/Livros e Fanzine } & \multicolumn{1}{c|}{ Datas } \\
\hline $\begin{array}{l}\text { Lívia Natália: Dia bonito pra chover } \\
\text { (Brasil) }\end{array}$ & $10 / 05 / 2019$ \\
$\begin{array}{l}\text { Luna Vitrolira: Aquenda - O Amor às vezes é } \\
\text { isso } \\
\text { (Brasil) }\end{array}$ & \\
\hline $\begin{array}{l}\text { May Ayim: Ser ou Não Ser } \\
\text { (Alemanha) }\end{array}$ & $28 / 06 / 2019$ \\
$\begin{array}{l}\text { Roberta Tavares: Mulheres de Fogo } \\
\text { (Brasil) }\end{array}$ & \\
\hline $\begin{array}{l}\text { Goretti Pina: A respiração dos dias } \\
\text { (São Tomé e Príncipe) }\end{array}$ & $13 / 09 / 2019$ \\
$\begin{array}{l}\text { Maíra Zenun: Receita para podar felicidade } \\
\text { (Brasil) }\end{array}$ & \\
\hline
\end{tabular}




\begin{tabular}{|l|l|}
\hline $\begin{array}{l}\text { Elisa Lucinda: A fúria da beleza } \\
\text { (Brasil) }\end{array}$ & $18 / 10 / 2019$ \\
$\begin{array}{l}\text { Odete Semedo: Entre o Ser e o Amar } \\
\text { (Guiné Bissau) }\end{array}$ & \\
\hline $\begin{array}{l}\text { Toni Morrison: Amada; Amor; Compaixão; } \\
\text { Deus ajude essa criança; O olha mais azul; } \\
\text { Paraíso; Pérola Negra. }\end{array}$ & $22 / 11 / 2019$ \\
\hline $\begin{array}{l}\text { Conceição Evaristo: Poemas de Recordação e } \\
\text { outros Movimentos. } \\
\text { (Brasil) }\end{array}$ & $13 / 12 / 2019$ \\
$\begin{array}{l}\text { Noémia de Sousa: Sangue Negro } \\
\text { (Moçambique) }\end{array}$ & \\
\hline
\end{tabular}

Seguem algumas imagens dos nossos Xirês Literários durante o ano de 2019.

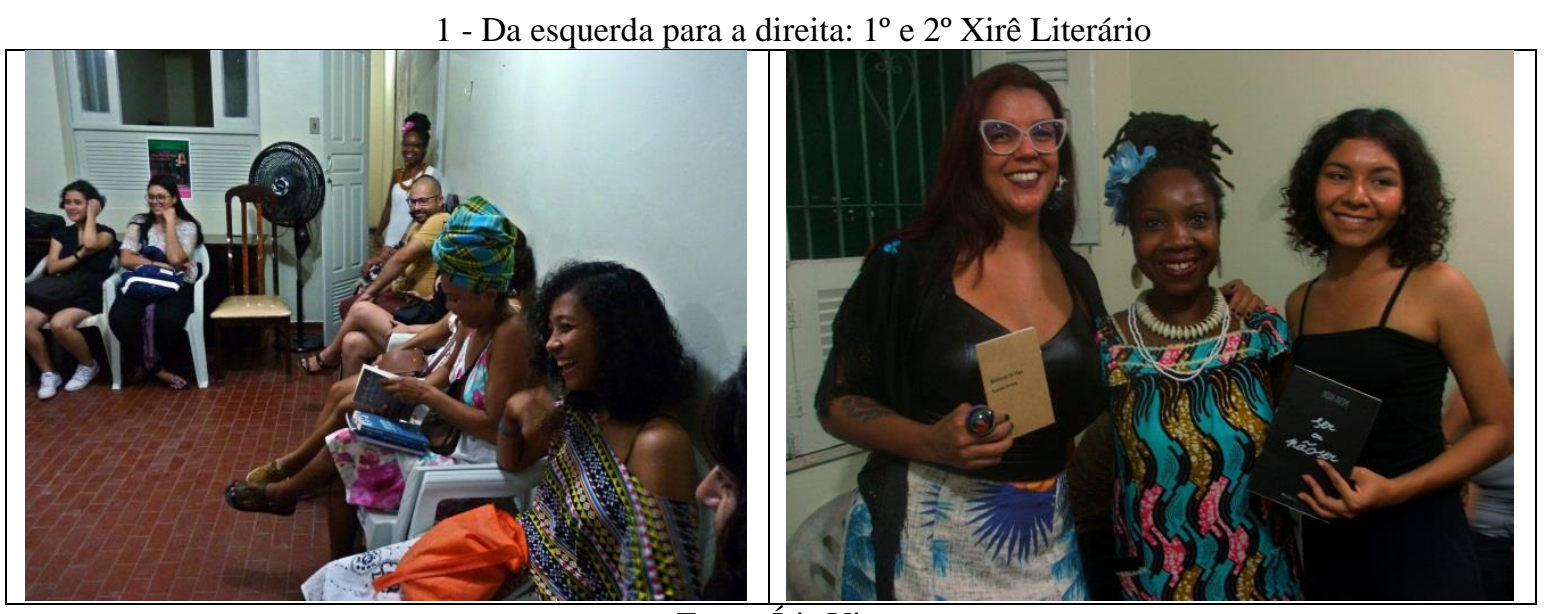

Fotos: Íris Viana

2 - Da esquerda para a direita: $3^{\circ}$ e $4^{\circ}$ Xirê Literário

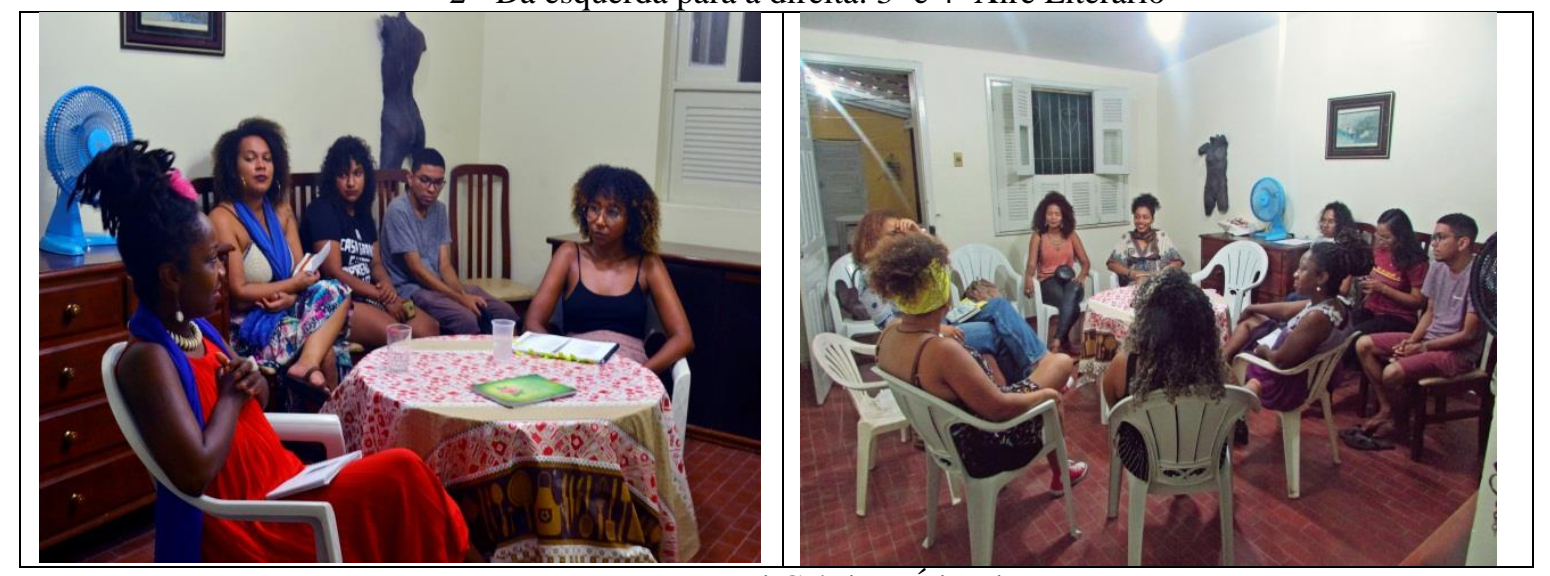

Fotos: Maryori Cabrita e Íris Viana

\footnotetext{
${ }^{6}$ No mês de novembro fizemos uma homenagem para a escritora estadunidense Toni Morison, com o Xirê Literário Roda Poética dos Afetos para Toni Morrison, devido ao seu falecimento em agosto de 2019.

Jangada| nr. 15, jan/jun, 2020 | ISSN 2317-4722

196 | Pá g i n a
} 


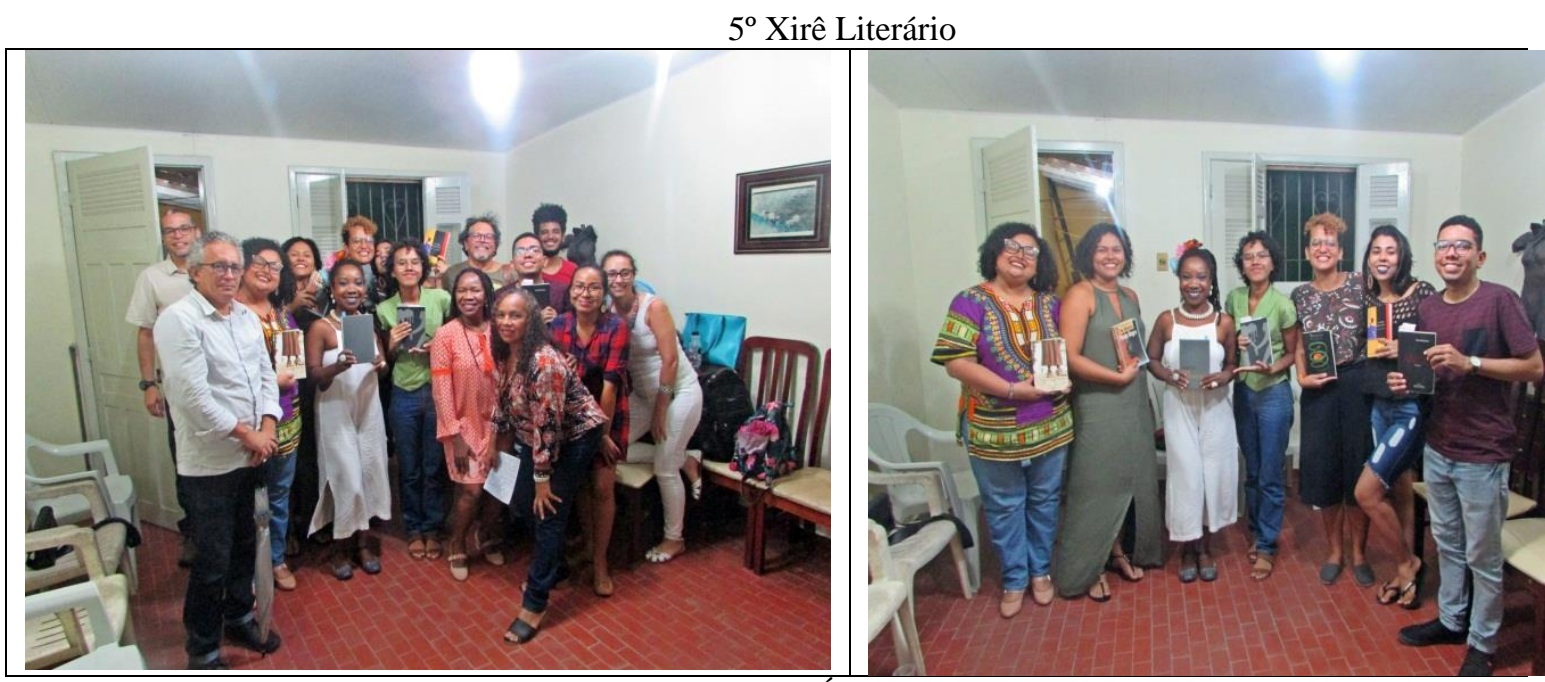

Fotos: Íris Viana

$6^{\circ}$ Xirê Literário

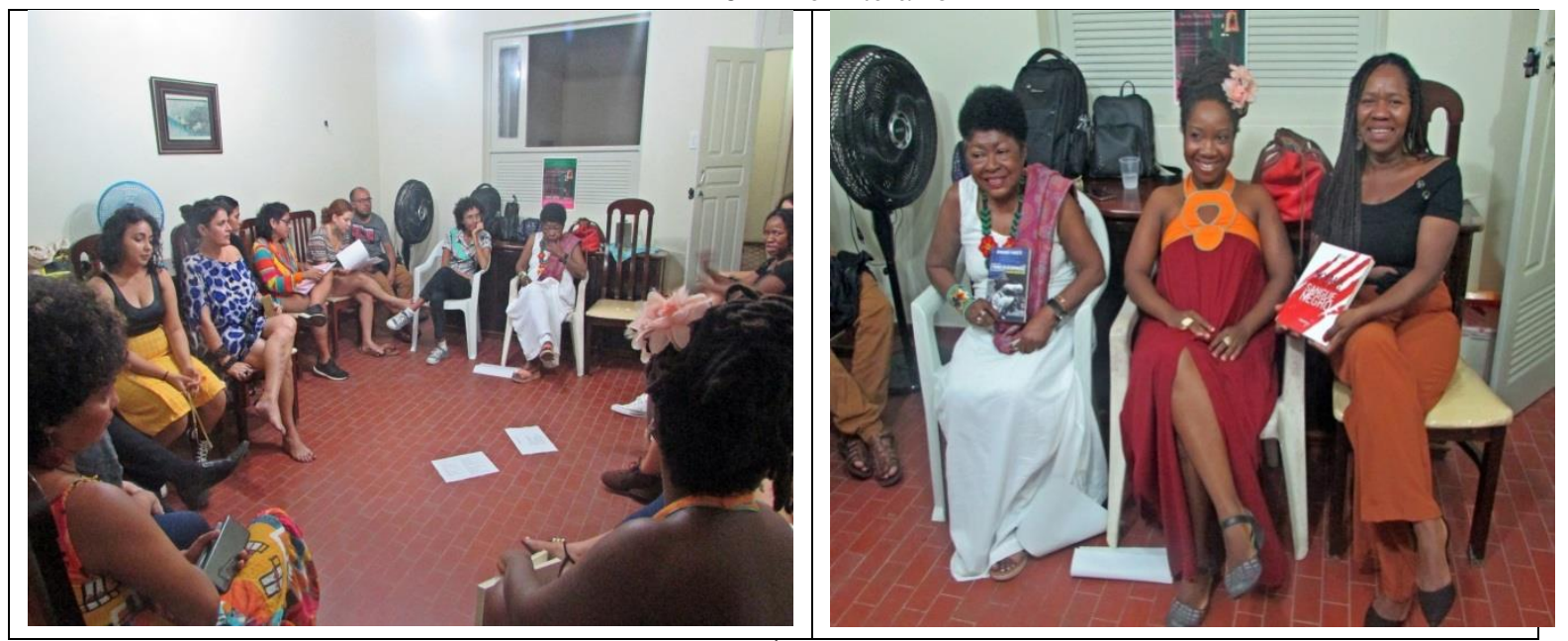

Fotos: Íris Viana

Registramos todas as sessões dos Xirês Literários, a responsável por realizar esse registro é Íris Viana, fotógrafa paraense e discente de Museologia. Esse acervo imagético além de ser exposto em nossas páginas nas redes sociais, também é uma forma de guardarmos essas memórias em fragmentos de imagens e apresentarmos a partir dos nossos negros olhares as nossas ações de existência e resistência. Como pesquisadoras e artVistas interessa-nos pensar essa sociedade do hoje com a qual interagimos no cotidiano vivido, e mais, tentamos vislumbrar de que forma os conhecimentos artísticos podem contribuir para estancar as veias rasgadas pelos resquícios coloniais ainda presentes na sociedade brasileira. As nossas memórias traumáticas são chagas abertas em lento processo de cicatrização, os fantasmas coloniais ainda habitam as nossas mentes e assombram os nossos corpos. 
Contudo, eventos como os Xirês Literários também são locais de cura, pois compartilhamos momentos de alegria e de encanto, especialmente neste ano de tristeza, angústia e desmonte das políticas sociais e de severos ataques à universidade pública e as/aos docentes. Mas, como nos lembra o autor indígena Ailton Krenak: “[...] a minha provocação sobre adiar o fim do mundo é exatamente sempre poder contar mais uma história." (KRENAK, 2019, p. 27). E nós resolvemos contar mais uma história em estado de poesia, porque é preciso que as palavras das poetas negras ecoem no tempo das águas de chuvas e rios, em Belém do Pará, principalmente:

Nesses tempos tão brutos que mais parece um eterno absurdo, onde não sabemos mais nada sobre tudo [...] diante dessa nuvem cinza que sombreia toda a América Latina, onde nós negras/negros e indígenas sabemos que estamos na mira há mais de quinhentos e tantos anos dos dias. E o que falar nessa Amazônia em chamas? ... que deixam nossos olhos ardendo e o sangue fervendo por dentro...” (GOMES, 2019, sítio web).

A beleza e a crueldade que a poesia nos oferta possibilita ter uma maior compreensão desse mundo belo e hostil criado por nós, seres humanos/as inacabados/as nessas tortuosas trilhas da vida. Porém, é preciso dessacralizar e desembranquecer a academia, os museus, os patrimônios, as epistemologias, as metodologias e as artes. Necessitamos com urgência ter uma atitude de descolonização das nossas mentes, temos que aprender a olhar por dentro antes de emitirmos palavras ao vento. É preciso expurgar o colonialismo patriarcal e racista das nossas geografias internas e criarmos mapas de saberes com os traços da equidade simétrica em coletivo.

\section{EM FASE DE CONSIDERAÇÕES FINAIS: QUAL É O LUGAR DA POESIA NOS ESTUDOS MUSEOLÓGICOS E PATRIMONIAIS?}

O lugar da poesia nos estudos museológicos e patrimoniais é provocar o desequilíbrio do branco conforto. É para nos obrigar a pensar que as memórias humanas extrapolam uma ficha catalográfica de um objeto bidimensional ou o tombamento de uma edificação antiga erguida no nefasto período colonial. É o lugar tensionador dos patrimônios imateriais que já fazem parte do gosto de uma elite branca, econômica e intelectual. A poesia, então, ocupa o lugar de 
construtora de outras memórias negras. É o lugar da cura de traumas coloniais que nos violentam até hoje em muitos museus e em patrimônios edificados.

Acreditamos no direito à memória que todas as pessoas devem ter. Realizamos um Projeto de Extensão como o Xirê da Leitura: Mulheres Negras Grafando Memórias em Letras de Poesia, por compreendermos que a poesia contemporânea produzida por mulheres negras brasileiras e estrangeiras, também possui relevância para o contexto nacional, da mesma forma que as artes criadas por pessoas brancas nacionais e internacionais, as quais conhecemos com certa propriedade, devido ao brancocentrismo permeante na academia e nos espaços oficiais de artes e memórias. Também é uma forma de executarmos na prática a Lei 10.639/20037 , que foi alterada para 11.645/2008 ${ }^{8}$ e, mesmo assim, após dezesseis anos constatamos que os princípios da Lei ainda não são executados com o destaque, o cuidado, o respeito e a seriedade que deve ter na maioria das Instituições Federais de Ensino Superior (IFES) e escolas. Sendo assim, a Museologia enquanto disciplina acadêmica precisa refletir criticamente sobre essa lei e a contínua seleção não natural dos fragmentos das memórias de pessoas brancas como vetores de uma "história nacional."

Para nós, pensarmos sobre o lugar da poesia produzida por mulheres negras nos estudos museológicos e patrimoniais, é uma forma de apresentar o lugar da inquietude que as nossas escritas ainda possuem no "clássico" mundo da arte literária e das ciências. Ainda hoje, precisamos demarcar, materializar e corporificar as nossas escritas para quebrarmos as correntes dos silenciamentos, do racismo e do sexismo. A filósofa Angela Davis já afirmou que: "Quando a mulher negra se movimenta, toda a estrutura da sociedade se movimenta com ela, porque tudo é desestabilizado a partir da base da pirâmide social onde se encontram as mulheres negras [...]”. (DAVIS, 2017, sítio web). Por isso, movimentar nos Xirês Literários, com as palavras de poetas negras em Belém do Pará, é uma forma de desestabilizar essa base racistamente normativa e de desestruturar os legados coloniais.

\footnotetext{
${ }^{7}$ A respectiva lei procurou alargar e aprofundar o ensino e " [...] o estudo da História da África e dos africanos, a luta dos negros no Brasil, a cultura negra brasileira e o negro na formação da sociedade nacional, resgatando a contribuição do povo negro nas áreas social, econômica e política pertinentes à História do Brasil." (LEI 10.639, 2003). Disponível em: http://www.planalto.gov.br/ccivil_03/leis/2003/110.639.htm, Acesso em 31/11/2019.

${ }^{8}$ A respectiva Lei: “Altera a Lei $\mathrm{n}^{\circ}$ 9.394, de 20 de dezembro de 1996, modificada pela Lei no 10.639 , de 9 de janeiro de 2003, que estabelece as diretrizes e bases da educação nacional, para incluir no currículo oficial da rede de ensino a obrigatoriedade da temática "História e Cultura Afro-Brasileira e Indígena." Disponível em: http://www.planalto.gov.br/ccivil_03/_Ato2007-2010/2008/Lei/L11645.htm
} Acesso em 06/12/2019. 
Por fim, tentamos construir nesse artigo um bordado letrado, costurado com as linhas das cordas vocais negras à deriva nas curvas do atlântico, executando um 'ballet' nas águas das chuvas a caminho da auscultação das memórias silenciadas. Lançar nosso olhar negramente feminista para as escritas de poetas negras nas margens de mares, rios e igarapés, é uma forma de adentrar e dessacralizar os espaços brancamente sagrados das escritas literárias e científicas com o nosso conhecimento corporificado a partir da pele que habitamos com indumentárias de letras em palavras descolonizantes.

\section{REFERÊNCIAS BIBLIOGRÁFICAS}

AKOTIRENE, Carla. O Que É Interseccionalidade? Coordenação Djamila Ribeiro. Belo Horizonte (MG): Letramento: Justificando, 2018. (Feminismos Plurais).

ANZALDÚA, Glória. Falando em línguas: uma carta para as mulheres escritoras do terceiro mundo [versão eletrônica]. In: Revista Estudos Feministas (pp.229-236). 2000. Disponível em: <https://periodicos.ufsc.br/index.php/ref/article/view/9880/9106>. Acesso em 12 dez. 2018.

DAVIS, Angela, "Quando a mulher negra se movimenta, toda a estrutura da sociedade se movimenta com ela". In: Reportagem cedida a Alê Alves para o Jornal El País em 27 de julho de 2017. Disponível em:

<https://brasil.elpais.com/brasil/2017/07/27/politica/1501114503_610956.html>.

Acesso em 10 jun. 2019.

EVARISTO, Conceição. "Nossa ESCREVIVÊNCIA reivindica o direito de contar as nossas histórias.” Oficina Memórias e Escrevivências. CENTUR, Belém do Pará, 2019.

GOMES, Luz. O que falar para Zélia Amador de Deus? 2019. Disponível em:

<https://etnografiasdemim.blogspot.com/2019/12/o-que-falar.html>.

Acesso em 06 dez. 2019.

GOMES, Luz. Em Curso. 2019. Disponível em:

<http://etnografiasdemim.blogspot.com/2019/02/em-curso.html>.

Acesso em 06 dez. 2019.

GONÇALVES, Ana Maria. O que a polêmica sobre o filme "Vazante" nos ensina sobre fragilidade branca. In: The Intercept_Brasil. 16 de novembro de 2017. Disponível em: https://theintercept.com/2017/11/16/o-que-a-polemica-sobre-o-filme-vazante-nos-ensinasobrefragilidade-branca/?comments $=1$ \#comments

Acesso em 10 dez. 2018.

KILOMBA, Grada. Memórias da Plantação - Episódios do Racismo Cotidiano. Tradução de Jess Oliveira. 1. Ed. Rio de Janeiro: Cobogó. 2019.

KRENAK, Ailton. Ideias para adiar o fim do mundo. $1^{\mathrm{a}}$ ed. São Paulo: Companhia das Letras, 2019.

LODRE, Audre. A Transformação do silêncio em linguagem e ação. In: Portal Geledés Instituto da Mulher Negra. (28/03/2015). Comunicação de Audre Lorde no painel "Lésbicas e 
literatura" da Associação de Línguas Modernas em 1977 e publicado em vários livros da autora. Disponível em:

<https://www.geledes.org.br/a-transformacao-do-silencio-em-linguagem-e-acao/> Acesso em 13 out. 2019.

LORDE, Audre. Poesia não é um luxo. In: diáspora y dissidência sexual em trânsito escritas negras/de cor feministas lésbicas cuíer/queer. Traduzido por Tatiana Nascimento em novembro de 2012. Publicado pela primeira vez em Chrysalis: A Magazine of Female Culture, n. 3 (1977). Nota da autora. Disponível em:

https://traduzidas.wordpress.com/2013/07/13/poesia-nao-e-um-luxo-de-audre-lorde/ Acesso em 13 out. 2019.

MBEMBE, Achille. Necropolítica: biopoder, soberania, estado de exceção, política da morte. Traduzido por Renata Santini. São Paulo: n-1 edições, 2018.

NATÁLIA, Lívia. "Eu sou uma mulher negra escrevendo": entrevista com Lívia Natália Por Graziele Frederico, Lúcia Tormin Mollo e Paula Queiroz Dutra. In: Estudos de literatura brasileira contemporânea, n. 51, p. 281-285, maio/ago. 2017. Disponível em:

<http://www.scielo.br/pdf/elbc/n51/2316-4018-elbc-51-00281.pdf>

Acesso em 13 out. 2019. 